\title{
A INSERÇÃO DOS PRINCÍPIOS DA EDUCAÇÃO AMBIENTAL NA UNIVERSIDADE TECNOLÓGICA FEDERAL: UMA ANÁLISE DOCUMENTAL
}

\author{
Dra ${ }^{a}$. Terezinha Corrêa Lindino \\ Universidade Estadual do Oeste do Paraná \\ Me. André Luís Quinelato \\ Instituto Federal do Paraná
}

RESUMO: Este artigo explora os mecanismos para a inserção da educação ambiental no cotidiano das universidades, selecionando-se a Universidade Tecnológica Federal do Paraná Câmpus Toledo como lócus da pesquisa. Procuramos analisar se os principios vinculados à educação ambiental são considerados na construção e manutenção dos documentos institucionais, incluindo-se o projeto político-pedagógico institucional (PPI), o plano de desenvolvimento institucional (PDI), os projetos pedagógicos dos cursos, além dos planos de ensino das disciplinas. Utilizou-se neste trabalho o método de análise documental para os documentos institucionais selecionados. Constatou-se que a temática ambiental e os principios vinculados à Educação Ambiental até estão inseridos nos documentos institucionais, porém não com o destaque devido e necessário, reduzindo-se a disciplinas optativas, ocasionando a disciplinarização e aprisionamento da temática ambiental no currículo dos cursos.

PALAVRAS-CHAVE: Educação Ambiental; Universidade Tecnológica Federal do Paraná; Demandas Ambientais no Ensino Superior.

\section{THE INTEGRATION OF THE PRINCIPLES OF ENVIRONMENTAL EDUCATION IN FEDERAL TECHNOLOGICAL UNIVERSITY: A DOCUMENTARY ANALYSIS}

\begin{abstract}
This article explores the mechanisms for the integration of environmental education into the daily life of universities, by selecting the Federal Technological University of Paraná - Campus Toledo as a place of research. We tried to analyze the principles related to environmental education are considered in the construction and maintenance of institutional documents, including the institutional political-pedagogical project (PPI), the institutional development plan (IDP), the pedagogical projects of the courses, in
\end{abstract}

addition to plans disciplines teaching. It was used in this study the document analysis method to selected institutional documents. It was found that environmental issues and principles related to environmental education until they are inserted in the institutional documents, but not with the highlight due and necessary, reducing the elective courses, causing the disciplining and imprisonment of environmental issues in the curriculum of courses. 


\section{INTRODUÇÃO}

Historicamente, os princípios defendidos pela Educação Ambiental podem ser analisados de várias formas. Neste sentido, diversas obras destacam que o ser humano não vive mais em uma natureza original e sim, vive em uma natureza transformada por sua ação, modificada pela sua história (CHARLOT; SILVA, 2005).

Partindo-se deste pressuposto, este artigo procura reunir autores consagrados no campo da Educação Ambiental nacional, de modo a apresentar discussões sobre a inserção dos princípios da Educação Ambiental na Universidade Tecnológica Federal do Paraná, mediante a análise de documentos institucionais (do Projeto Político-Pedagógico Institucional até os projetos pedagógicos e planos de ensino dos cursos de graduação) existentes na unidade pesquisada.

Optou-se pela utilização do método de análise documental, procurando avaliar se a temática ambiental e os princípios vinculados à Educação Ambiental são inseridos nos currículos adotados e de que forma isso ocorre. Sendo assim, este estudo baseou-se nos princípios defendidos pela Educação Ambiental surgidos em um contexto de crise ambiental, visto que os mesmos estruturaramse como uma forte demanda para que o ser humano adotasse uma visão de mundo e uma prática social capazes de minimizar os impactos ambientais então prevalecentes (LAYRARGUES; LIMA, 2011). Inicialmente devemos destacar que a Educação Ambiental e os seus princípios não devem se restringir apenas em “[...] garantir a preservação de determinadas espécies animais e vegetais e dos recursos naturais" (REIGOTA, 1998, p. 08), tendo em vista que não é raro observarmos afirmações de que a Educação Ambiental resume-se ao ensino conceitos vinculados à ecologia, biologia ou geografia, reduzindo-se o seu campo de interesse e ação. Concordamos com Reigota (1998) quando o autor adverte que para se apresentar uma proposta de Educação Ambiental é necessário ter antes uma definição clara de Meio Ambiente que a sustente.

[...] um lugar determinado e/ou percebido onde estão em relações dinâmicas e em constante interação os aspectos naturais e sociais. Essas 
relações acarretam processos de criação cultural e tecnológica e processos históricos e políticos de transformação da natureza e da sociedade (REIGOTA, 1998, p. 21).

O autor defende a ideia de que o Meio Ambiente não é sinônimo de meio natural, razão pela qual a Educação Ambiental não é sinônimo de ensino de ecologia, embora não prescinda da mesma. Na verdade ela deve estar presente em todas as disciplinas, quando analisa temas que permitem enfocar as relações entre a humanidade e o meio natural, e as relações sociais, sem deixar de lado as suas especificidades (REIGOTA, 1998).

Mas, como o campo educacional está refletindo e até mesmo praticando esta ideia em seus cursos? Nota-se que a tradicional separação entre as disciplinas deveria perder seu sentido, já que o que se busca é o conhecimento integrado de todas elas para a solução dos problemas ambientais.

Mais ainda, por entender que a questão ambiental engloba aspectos políticos, econômicos, culturais e sociais, os princípios problematizados pela Educação Ambiental poderiam ser incorporados nos currículos de graduação e pós-graduação, quando tratados no Ensino Superior. Esta afirmação ganha credibilidade quando se analisa a definição de Educação Ambiental presente na Lei $n^{\circ}$ 9795/99, que define a Educação Ambiental como:

[...] processos por meio dos quais o indivíduo e a coletividade constroem valores sociais, conhecimentos, habilidades, atitudes e competências voltadas para a conservação do meio ambiente, bem de uso comum do povo, essencial à sadia qualidade de vida e sua sustentabilidade (BRASIL, 1999, Art. $1^{\circ}$ ).

Essa definição permite refletir sobre a complexidade, mas necessária, articulação entre os saberes para agir em prol da sustentabilidade socioambiental e, consequentemente, discutir a melhoria da qualidade de vida da população, já que é consenso que a Educação Ambiental deve estar presente em todos os espaços que educam os cidadãos.

Segundo Reigota (1998), atualmente, a Educação Ambiental está sendo realizada em escolas, parques, reservas ecológicas, associações, sindicatos, universidades, meios de comunicação, dentre outros. Mas será que ela está influenciando o cotidiano nesses espaços e provocando rupturas? Será que está 
desenvolvendo contrapontos às ideias existentes e superando preconceitos? Ou ainda, será que ela está conseguindo exaltar a pluralidade de pontos de vista e concepções ideológicas?

Grün aposta na Educação Ambiental, de modo a entender que ela promove uma “[...] discussão, tematização e reapropriação de certos valores” (2012, p. 22). Todavia, observa-se em nossa sociedade escolar, por exemplo, ainda a adoção de valores mais imediatos da consciência; valores que não problematizam as raízes da crise socioambiental contemporânea. Ou seja, "[...] por esta razão se relaciona a crise ecológica a uma crise da cultura ocidental. Seria parte da tarefa de uma Educação Ambiental proceder a uma tematização a respeito dos valores que regem o agir humano em sua relação com a natureza" (GRÜN, 2012, p. 22).

Consequentemente, é justamente no processo de afirmação de valores de dominação e exploração da natureza que se encontra a supressão de um conjunto de valores, servindo de referência sobre a qual iria se legitimar as ideias e fundamentos predominantes até os dias atuais, o racionalismo moderno. Corroborando a concepção de Grün (2012), mais do que criar novos valores, a Educação Ambiental deveria se preocupar em resgatar alguns valores já existentes, que foram reprimidos pelo racionalismo e pensamento científico moderno (dentre esses valores destaca-se a solidariedade, a cooperação, o caráter e a compreensão).

Paralelamente, Sorrentino et al. (2005) apresentam uma concepção de Educação Ambiental como uma possivel estratégia para o enfrentamento da crise civilizatória cultural e social. Ela visa à superação das injustiças ambientais, da desigualdade social, da apropriação capitalista e funcionalista da natureza e da própria humanidade, numa perspectiva de transformação social, pois entende que a crise ambiental seria um reflexo da crise da humanidade, dos meios de produção e dos padrões de consumo da sociedade contemporânea.

Mostra-se como uma necessidade no ensino formal, perpassando todos os niveis e modalidades educacionais para o enfrentamento da crise socioambiental, numa postura coletiva em contrapartida aos ideários individualistas. Neste contexto, torna-se necessário examinar e discutir os desdobramentos dos 
princípios da EA no Ensino Superior e quais são os processos de fortalecimento desta relação.

\section{Educação Ambiental no ensino superior - a importância das diretrizes curriculares nacionais}

Ao apresentar um panorama sobre as políticas públicas existentes que abordam a relação entre a inserção das questões ambientais e os principios da Educação Ambiental (EA) no ensino superior, bem como os efeitos deste processo relacional, indica-se a necessidade da inserção desses princípios nos documentos institucionais das instituições de ensino superior, incluindo-se os projetos e os currículos dos cursos superiores.

Autores como Sorrentino et al. (2005) entendem politica como limite e como uma regulação dialética sociedade-Estado que favoreça a pluralidade, igualdade social e política. A questão ambiental e de toda sociedade e a complexidade em torno dessas questões exigia, neste panorama, a regulação e a inserção do Estado.

O ambientalismo coloca-nos a questão dos limites que as sociedades têm na sua relação com a natureza, com suas próprias naturezas como sociedades. Assim, resgatar a política é fundamental para que se estabeleça uma ética da sustentabilidade resultante das lutas ambientalistas. Segundo os autores,

\footnotetext{
Considerando a ética da sustentabilidade e os pressupostos da cidadania, a politica pública pode ser entendida como um conjunto de procedimentos formais e informais que expressam a relação de poder e se destina à resolução pacífica de conflitos, assim como à construção e ao aprimoramento do bem comum (SORRENTINO et al. 2005, p. 289).
}

Sua gênese está nas questões que afetam a sociedade e se tornam públicas, numa maneira de solucionar essas demandas. Um exemplo é a política nacional referente à EA, que reforça a responsabilidade coletiva da sua implementação, seus principios e objetivos.

O envolvimento na luta pelo bem-estar socioambiental deve ser um conjunto de ações, envolvendo uma série de atores e instituições coletivas, em contrapartida às concepções individualistas de enfrentamento da crise ambiental. Do mesmo modo, na perspectiva de formulação de políticas públicas sobre os princípios 
defendidos pela EA, entende-se como necessária a garantia da inserção da prática coletiva e dialógica nas universidades por meio de documentos norteadores e como práxis científica e educacional.

A lei $n^{\circ}$ 9795/1999 traz, em seu Art. 9ª a preocupação em inserir no currículo da educação superior os princípios problematizados pela EA, em instituições públicas e privadas. Além desta preocupação com sua inserção no currículo dos cursos de graduação nas instituições de ensino superior, há o entendimento da participação das universidades na formulação e execução de programas e atividades vinculadas à EA dentro e fora de seus limites.

O Conselho Nacional de Educação, por meio da Resolução $n^{\circ}$ 2, de 15 de junho de 2012, publicado no Diário Oficial da União em 18 de junho de 2012, estabeleceu as Diretrizes Curriculares Nacionais para a Educação Ambiental. Traz importantes apontamentos do trabalho a partir dos princípios defendidos pela EA em todos os niveis de ensino. Especificamente para as instituições de ensino superior, tais princípios sugerem o aprofundamento do pensamento reflexivo a partir da dimensão socioambiental, valorizando a participação, a cooperação, o senso de justiça e a responsabilidade da comunidade educacional em contraposição às relações de dominação e exploração presentes na realidade atual (BRASIL, 2012).

Outra característica fundamental é o estímulo à constituição de instituições de ensino como espaços educadores sustentáveis, integrando proposta curricular, gestão democrática e edificações tornando-as referências de sustentabilidade socioambiental (BRASIL, 2012). Sendo assim, o Art. $15^{\circ}$ das Diretrizes Curriculares Nacionais para a Educação Ambiental traz o entendimento que o papel socioeducativo, ambiental, artístico, cultural e as questões de gênero, etnia, raça e diversidade que compõem as ações educativas, acrescidas da organização e gestão curricular, são componentes integrantes dos projetos institucionais e pedagógicos da educação, incluindo-se a Educação Superior.

Traz também em seu teor que a proposta curricular é constitutiva do Projeto Político-Pedagógico (PPP), dos Projetos e Planos de Cursos (PC) das instituições de Educação Básica, dos Projetos Pedagógicos de Curso (PPC) e do Projeto Pedagógico 
(PP) constante do Plano de Desenvolvimento Institucional (PDI) das instituições de Educação Superior (BRASIL, 2012).

Ressalta-se aqui o Art. $24^{\circ}$ das DCNEAs que disciplina que os órgãos competentes devem incluir o atendimento deste documento nas avaliações para fins de credenciamento, recredenciamento, autorização e renovação de autorização de instituições educacionais e de cursos superiores. Por conseguinte, há necessidade de se garantir que essas ações se efetivem no cotidiano universitário e nos documentos institucionais das IES.

Para averiguar essas questões e seus desdobramentos no interior dos principais documentos da UTFPR - Câmpus Toledo, a seguir será apresentado os mecanismos e técnicas utilizadas para a investigação científica.

Caracterizada como uma pesquisa de cunho qualitativo optou-se pela adoção das técnicas de análise documental para a apreensão da realidade no lócus da pesquisa. A Universidade Tecnológica Federal do Paraná (UTFPR) foi o objeto de estudo selecionado. A escolha por essa instituição não foi aleatória, visto que ela é a única Universidade Tecnológica do Brasil e referência nacional na área tecnológica.

A UTFPR destaca-se por sua estrutura multicampi, distribuída pelas cidades de Apucarana, Campo Mourão, Cornélio Procópio, Curitiba, Dois Vizinhos, Francisco Beltrão, Guarapuava, Londrina, Medianeira, Pato Branco, Ponta Grossa, Toledo e Santa Helena, englobando praticamente todas as regiões do Paraná. Para este estudo, escolhe - se o câmpus da UTFPR na cidade de Toledo, devido ao mesmo ser um dos primeiros do sistema a iniciar suas atividades não mais como uma unidade descentralizada do antigo CEFET-PR (Centro Federal de Educação Tecnológica do Paraná), mas já como câmpus universitário, apresentando peculiaridades não vistas em outras localidades onde a universidade está inserida.

A instalação oficial do câmpus da UTFPR em Toledo ocorreu em 05 de fevereiro de 2007, por meio da expansão da rede pública federal de ensino. O quadro 1 apresenta a visão geral dos cursos ofertados pela instituição no ano em que a coleta foi realizada. 
Quadro 1. Cursos do Câmpus de Toledo

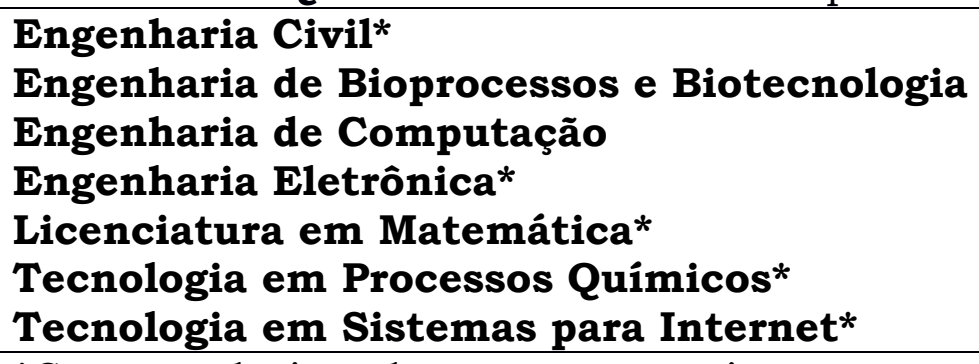

Fonte: UTFPR (2014a).

Foram excluídos os cursos de Engenharia de Computação e de Engenharia de Bioprocessos e Biotecnologia por serem novos, com implantação no início do ano de 2015. Entende - se que eles não apresentariam material suficiente para a investigação científica pretendida.

A intenção do uso da técnica de levantamento bibliográfico foi para explorar os conhecimentos existentes sobre os assuntos que convergem com o objeto de nosso estudo (GALVÃO, 2010). Para tanto, utilizou-se a técnica de levantamento documental, procurando coletar dados sobre a UFTPR, no que se refere à sua história, sua missão e seus valores institucionais. As fontes pesquisadas foram: o Projeto Político Pedagógico Institucional (PPI), o Plano de Desenvolvimento Institucional (PDI) e o Regimento Geral no plano macro institucional. O PPI e o PDI são documentos que contemplam os rumos a serem seguidos por toda a Instituição. Já o PPC e o PE são documentos que ponderam as ações a serem seguidas pelos colegiados existentes no lócus da pesquisa.

Do Câmpus Toledo, selecionaram-se o Regimento dos Câmpus da UTFPR, os Projetos Pedagógicos dos Cursos (PPC) do Câmpus de Toledo e os Planos de Ensino (PE), especificamente as ementas que apresentassem conteúdos referentes às questões socioambientais analisadas.

Principios e Visões da EA nos Documentos Institucionais e nos Projetos de Curso de uma Universidade Tecnológica Federal 
Ao analisar conjuntamente o Projeto Político Pedagógico Institucional (PPI) e o Plano de Desenvolvimento Institucional (PDI) da UTFPR, buscam-se encontrar quais convergências eles apresentam para a inserção dos principios defendidos pela EA no ensino superior e suas práticas sustentadas.

O Projeto Político-Pedagógico Institucional (PPI) é o principal documento institucional da Universidade Tecnológica, e é por meio dele que outros documentos institucionais são gestados, incluindo-se o Plano de Desenvolvimento Institucional (PDI). O documento problematiza o significado de tecnologia e sua influência e importância na sociedade, na medida em que a tecnologia deve assumir o "[...] papel central na sociabilidade, ou seja, na produção da realidade e do imaginário (universo real e simbólico)" (LIMA FILHO; QUELUZ, 2005, p. 19). Ainda de acordo com os autores, a tecnologia, mais que força material da produção, torna-se imbricada e indissociável das práticas cotidianas, assumindo plenamente uma dimensão sociocultural, uma centralidade na produção da sociabilidade, provocando impactos e soluções das mais variadas ordens para toda a sociedade.

Importante pontuarmos que as instituições de ensino superior devem inserir os princípios da EA no cotidiano universitário a partir dos seus documentos norteadores, conforme consta nas Diretrizes Curriculares Nacionais para a Educação Ambiental. As universidades devem mostrar no PPI como integra tais principios à sua administração e aos cursos de graduação (por exemplo, como é o desenvolvimento de projetos institucionais, acadêmicos, de extensão e de pesquisa). Aliado a essa ideia, o Art. $2^{\circ}$ das Diretrizes Curriculares Nacionais para a Educação Ambiental, traz o entendimento da Educação Ambiental como uma das dimensões da Educação e que a ela imprime o desenvolvimento de um caráter social sobre a relação homem-natureza, com a finalidade de torná-la uma prática ética ambiental (BRASIL, 2012).

Esse entendimento torna-se essencial para a UTFPR, pois, um dos desafios que a instituição se propõe a fazer é contribuir com o avanço da educação profissional e tecnológica, compreendendo que o exercício das atividades humanas "não se restringe ao caráter produtivo, mas compreende todas as dimensões: social, política, cultural e ambiental” (UTFPR, 2007a, p. 62). Logo, a 
UTFPR demonstra a necessidade e a importância de pautar suas ações e ideologias baseadas nessas diretrizes, uma vez que defende que todos os cursos por ela ofertados devem problematizar e promover a relação dinâmica entre tecnologia e os problemas contemporâneos, entendendo a tecnologia como uma ferramenta para a mitigação das mazelas da sociedade atual.

A tecnologia, uma marca indissociável da identidade da UTFPR, não deve restringir-se a um processo de aplicação ou desenvolvimento de processos ou protótipos direcionados a fins úteis. O PPI da UTFPR defende a concepção de educação tecnológica que forme um profissional com capacidade de interagir em situações novas e em constante mutação, pois essa realidade "[...] exige níveis de qualificação e educação mais elevados e o desenvolvimento de competências cognitivas mais complexas, que vão além da competência técnica” (UTFPR, 2007a, p. 63). Por conseguinte, os cursos da instituição devem fomentar uma formação diversificada, destacando a flexibilização curricular, buscando alternativas para a resolução de problemas técnicos e sociais (UTFPR, 2012a).

O PPI destaca ainda a necessidade de formação integral do cidadão, como sujeito autônomo, que se preocupe com a preservação do ambiente, dos recursos naturais, das formas de vida do planeta, dos valores éticos e morais comprometidos com a ética da vida (UTFPR, 2007a).

Além do PPI, um documento fundamental para os rumos da UTFPR é o PDI, desenvolvido para o período de 2013-2017. Nele destaca-se a missão institucional que se fundamenta no desenvolvimento da Educação Tecnológica de excelência por meio do ensino, pesquisa e extensão, interagindo de forma ética, sustentável, produtiva e inovadora com a comunidade para o avanço do conhecimento e da sociedade (UTFPR, 2013a).

Ao analisarmos as metas prescritas no PDI, verifica-se a presença de atividades de sustentabilidade nas ações de ensino, pesquisa e extensão sob a administração das Pró-Reitorias correlatas, incentivando também a adoção da metodologia interdisciplinar como forma de integração das diferentes áreas de conhecimento, bem como das diferentes disciplinas. A interdisciplinaridade, neste sentido, não deve ser vista como negação da disciplina, na medida em que propõe sua superação. Trindade aponta que 


\begin{abstract}
A prática interdisciplinar pressupõe uma desconstrução, uma ruptura com o tradicional e com o cotidiano tarefeiro escolar. O professor interdisciplinar percorre as regiões fronteiriças flexiveis onde o eu convive com o outro sem abrir mão de suas características, possibilitando a interdependência, o compartilhamento, o encontro, o diálogo e as transformações. Esse é o movimento da interdisciplinaridade caracterizada por atitudes ante o conhecimento (TRINDADE, 2008, p. 82).
\end{abstract}

Tanto o PDI como os projetos de cursos apresentam a preocupação em não formar apenas mão de obra para o mercado de trabalho, mas profissionais críticos, por meio de atividades diversificadas ao longo da sua formação. A interdisciplinaridade pode possibilitar essa diversificação da formação dos discentes nos cursos de graduação, pautado principalmente na conexão dos saberes e o estudo de problemáticas que afligem a sociedade como um todo, que podem ser comuns a diversas disciplinas.

O PDI da UTFPR também aponta caminhos para a elaboração dos projetos de cursos da instituição, enfatizando a necessidade de se levar em consideração a formação generalista, humanista, critica e reflexiva, capaz de absorver novas tecnologias, considerando os aspectos globais que interferem na sociedade. Com base neste panorama, nota-se que os cursos, de uma forma geral, procuram desenvolver um currículo que articulem a teoria e a prática, bem como a flexibilização e a articulação entre ensino, pesquisa e extensão (UTFPR, 2014b).

Os cursos devem, além disso, incorporar aspectos diversificados na formação dos seus acadêmicos, inserindo discussões de caráter político, econômico, social, ambiental e cultural em diferentes disciplinas, com visão ética e humanística, em atendimento às demandas da sociedade. Porém, observa-se na maioria dos cursos que essas discussões acabam sendo inseridas em disciplinas optativas e de forma não contínua, dificultando o perfil de formação diversificado, sugeridos pelo PPI e PDI da universidade.

A UTFPR exige que os objetivos norteadores para a elaboração e atualização dos projetos dos cursos devem ter como referencial a missão, a visão e os valores da universidade tecnológica. O primeiro curso analisado, de Engenharia Civil, buscou limitar os conteúdos obrigatórios àqueles realmente essenciais à formação do Engenheiro, sendo que algumas disciplinas específicas inserem visões sociais e ambientais dos problemas relacionados à construção civil, tendo em vista que o 
projeto "foi estruturado para a formação de um profissional capaz de propor soluções não apenas tecnicamente corretas, mas que contemplem também uma visão humanística e ambiental dos problemas” (UTFPR, 2014b, p. 32).

No que tange à inserção dos princípios defendidos pela EA, dentre os cincos cursos analisados, as disciplinas do curso de Engenharia Civil foram as que mais se aproximaram da utilização desses princípios. Elas são apresentadas no quadro 2:

Quadro 2. Disciplinas do curso de Engenharia Civil que possibilitam o trabalho com os principios da EA

\begin{tabular}{|c|c|}
\hline DISCIPLINA & CARACTERÍSTICAS \\
\hline $\begin{array}{l}\text { Quimica dos } \\
\text { Materiais }\end{array}$ & $\begin{array}{l}\text { Aborda principalmente a problemática da água, trabalhando } \\
\text { questões como poluição, tratamento, qualidade, parâmetros } \\
\text { químicos e físicos para consumo humano/industrial e } \\
\text { legislação. }\end{array}$ \\
\hline $\begin{array}{l}\text { Ciências do } \\
\text { Ambiente }\end{array}$ & $\begin{array}{l}\text { Proporciona conceitos de ecologia, ciências ambientais e } \\
\text { educação ambiental que possam ser aplicados na } \\
\text { engenharia. }\end{array}$ \\
\hline Transportes & $\begin{array}{l}\text { Discute a relação transporte e sociedade, de modo a tratar } \\
\text { os impactos ambientais dos sistemas de transporte. }\end{array}$ \\
\hline $\begin{array}{l}\text { Ética, Profissão } \\
\text { e Cidadania }\end{array}$ & $\begin{array}{l}\text { Analisa a atuação do engenheiro sob o ponto de vista ético e } \\
\text { moral. Discute o papel do profissional como cidadão e suas } \\
\text { vinculações com a sociedade sob o aspecto legal. }\end{array}$ \\
\hline $\begin{array}{l}\text { Obras } \\
\text { Hidráulicas }\end{array}$ & $\begin{array}{l}\text { Apresenta o entendimento dos aspectos ambientais e } \\
\text { multidisciplinares envolvidos em obras hidráulicas e } \\
\text { metodologia para identificar áreas com minimas restrições } \\
\text { ambientais possiveis à construção de barragens. }\end{array}$ \\
\hline Sane & $\begin{array}{l}\text { Proporciona uma visão dos aspectos ambientais envolvidos } \\
\text { no saneamento, critérios de qualidade, poluição e } \\
\text { preservação dos corpos d'água. Proporciona ainda uma } \\
\text { noção dos principios de manejo de águas pluviais urbanas, } \\
\text { além de tratamento de esgoto e disposição final dos esgotos. }\end{array}$ \\
\hline $\begin{array}{l}\text { Gerenciamento } \\
\text { de Recursos } \\
\text { Hidricos }\end{array}$ & $\begin{array}{l}\text { Desenvolve a avaliação e gerenciamento dos aspectos legais, } \\
\text { institucionais, politicos e técnicos dos recursos hídricos. }\end{array}$ \\
\hline $\begin{array}{l}\text { Conforto } \\
\text { Ambiental }\end{array}$ & $\begin{array}{l}\text { Define o que é arquitetura sustentável, edificações } \\
\text { sustentáveis, gestão ambiental de áreas degradadas e a } \\
\text { avaliação de impacto ambiental. }\end{array}$ \\
\hline $\begin{array}{l}\text { Construções } \\
\text { Sustentáveis, } \\
\text { Metodologia e } \\
\text { Tecnologia }\end{array}$ & $\begin{array}{l}\text { Trata de temática sobre o desenvolvimento e a conservação } \\
\text { do meio ambiente; a geração de residuo da construção e } \\
\text { demolição; reaproveitamento e recuperação de materiais na }\end{array}$ \\
\hline
\end{tabular}




\begin{tabular}{|l|l|}
\hline & $\begin{array}{l}\text { construção civil; processos de construção alternativa; } \\
\text { utilização de baixo consumo energético e design ecológico. }\end{array}$ \\
\hline $\begin{array}{l}\text { Meio Ambiente } \\
\text { e Sociedade }\end{array}$ & $\begin{array}{l}\text { Debate a crise socioambiental e os desafios para o } \\
\text { desenvolvimento em bases sustentáveis, apropriando-se de } \\
\text { conhecimentos que orientem a mudança social. }\end{array}$ \\
\hline
\end{tabular}

Fonte: Projeto Pedagógico do Curso de Engenharia Civil (2014b)

Como o foco do curso é a área de construção civil, as disciplinas tenderam a inserir discussões sobre construções sustentáveis, perpassando a atuação do engenheiro sob o ponto de vista ético e moral e sua vinculação com a sociedade. O PPI apresenta que o cenário produtivo, que vem se delineando desde o final do século XX, passou a exigir um novo perfil profissional com capacidade de interagir em situações novas e em constante mutação (UTFPR, 2007a). Torna-se fundamental a inserção de discussões a respeito do papel do engenheiro na busca de um ambiente equilibrado, pautando suas ações visando a melhoria do bem estar socioambiental da sociedade global.

Para a construção do PPC do curso de Engenharia Eletrônica, o documento destaca a contribuição do curso com a UTFPR como um todo, pois proporciona inovação, qualidade, desenvolvimento humano, dentre outros valores que fazem parte do PDI da UTFPR. A justificativa para a inserção do curso no estado do Paraná e, mais especificamente em Toledo, foi o elevado potencial industrial da região, além da elevada produção agrícola, o que demanda dispositivos para automação e recursos informatizados que possam ser projetados e disponibilizados visando a gestão mais eficiente dessa produção (UTFPR, 2012b).

As novas tecnologias, incluindo a eletrônica, estabeleceram uma reorganização da produção, exigindo profissionais que possuam competências para projetar, executar e manter produtos e serviços que dinamizem o referido processo (UTFPR, 2012b). Assim, este curso, a fim de atender a missão e visão da UTFPR, buscou enfatizar a formação tecnológica aliada a uma formação social, capaz de alavancar o desenvolvimento da região.

Dentre os objetivos do curso está a necessidade de desenvolver "[...] no profissional a ética, a segurança, a legislação e os impactos ambientais" (UTFPR, 
2012 b, p. 18). Além disso, consta a necessidade de aprimoramento da atuação em equipes multidisciplinares e de formação generalista.

A análise das disciplinas do curso mostra que as convergências encontradas apontam para a integração das atividades de engenharia no contexto social e ambiental. Dentre as disciplinas destinadas ao núcleo de conteúdos básicos, estão as especificidades de Ciências do Ambiente e de Humanidades, Ciências Sociais e Cidadania, que podem contribuir com o panorama anteriormente descrito. Apesar destas constatações, a análise das ementas e conteúdos mostrou que são poucas as disciplinas que abordam a relação meio ambiente e sociedade. São elas: Introdução à Engenharia, ofertada no $1^{\circ}$ semestre; Sociedade e Politica no Brasil, Ciências do Ambiente e Tecnologia e Sociedade, ofertadas como optativas, reduzindo as questões socioambientais a momentos dispersos ao longo do curso.

Já no curso de Licenciatura em Matemática, o PPC traz como objetivo principal a formação de profissionais para atuarem como professores de Matemática da Educação Básica (Ensino Fundamental II e Ensino Médio). O documento destaca que as disciplinas foram escolhidas de modo a contemplar os diversos âmbitos do conhecimento deste tipo de profissional (UTFPR, 2014a). Ele também considerou como um dos princípios o desenvolvimento da visão crítica de preservação e conservação do meio ambiente ao possibilitar a compreensão da relação homem-ambiente-tecnologia-sociedade, provendo ações que são defendidas pela Educação Ambiental, no que tange à preservação da biodiversidade e à melhoria da qualidade de vida (UTFPR, 2014a). Aponta, contudo, que tais ações precisam ser melhor direcionadas dentro do curso para proporcionar o entendimento complexo e diversificado de ambiente, além de subsídios para atuação frente aos problemas desencadeados pelo processo de modernização.

O próprio projeto enfatiza que os principios defendidos pela EA são pertinentes e necessários em todos os niveis de ensino e deveriam ser praticados por todos os docentes. Destaca, ademais, que devido às questões de natureza socioambiental estar presentes em nosso cotidiano, o curso deveria compreender a complexidade e a importância dessas questões para contribuir “[...] na formação de sujeitos conhecedores de seus direitos e deveres, bem como conscientes de seu 
papel frente à construção de um mundo sustentável e responsável” (UTFPR, 2014a, p.98).

O PPC do curso de Licenciatura em Matemática traz um tópico específico sobre os princípios defendidos pela EA, integrando-os em programas de extensão, iniciação científica e, principalmente, nas disciplinas do curso. Esse documento aponta que as discussões ambientais acabam sendo realizadas de modo contínuo, permanente e transversal em suas disciplinas. Porém, a análise documental mostrou que, de fato, somente uma disciplina apresenta o cunho socioambiental na grade curricular do curso - a disciplina de Meio Ambiente e Sociedade (inserida por meio do processo $\mathrm{n}^{\circ}$ 033/13-COGEP). Sua inclusão respondeu a legislação sobre a temática (Lei $\mathrm{n}^{\circ}$ 9.795, de 27/04/1999). Ao analisar os PE das disciplinas, apesar do PPC citar outras disciplinas que podem ser relacionadas aos princípios defendidos pela EA, a disciplina de Meio Ambiente e Sociedade foi a única no projeto pedagógico de curso a explicitar tal objetivo.

Já o PPC de Tecnologia em Processos Químicos procura formar um profissional com visão sistêmica e criativa. Ele deve possuir um perfil mais generalista, no qual consolide a formação em aspectos de segurança, meio ambiente, qualidade, técnicas analíticas e gerenciamento da produção (UTFPR, 2007b). Analisando as disciplinas do referido curso, percebe-se que o foco do curso na área ambiental é com relação à preservação do meio natural, e são poucos os momentos de reflexão sobre a relação entre sociedade, meio ambiente e desenvolvimento. A maioria das disciplinas relaciona-se com questões como controle de resíduos, poluição ambiental, reciclagem e desenvolvimento sustentável, visando principalmente soluções técnicas para o impacto ocasionado por indústrias do setor químico.

O projeto de abertura do curso de Tecnologia em Sistemas para Internet defende a formação do profissional da área focando no desenvolvimento de soluções técnicas relacionadas à Internet. Assim o curso tem como objetivo a capacitação de recursos humanos para atuação no mercado de trabalho que demanda uso de Tecnologias de Informação e Comunicação (UTFPR, 2013b).

Apesar do foco do curso voltar-se para a formação de profissionais com domínio para o desenvolvimento de programas, interfaces, aplicativos, além de 
páginas e portais para internet e intranet, o projeto de abertura do curso destaca que o período de vida acadêmica proporciona ao discente a oportunidade de se socializar, amadurecendo e consolidando sua formação cidadã. Neste sentido, a oferta do curso vai além da formação técnica específica, pois a inserção do estudante na comunidade acadêmica da UTFPR traz consigo a possibilidade de atuar nas entidades estudantis, e por consequência no debate envolvendo questões culturais, sociais, econômicas e sua influência no desenvolvimento humano e social (UTFPR, 2013b).

Além disso, de maneira complementar, o curso espera formar um profissional com atitude proativa de autonomia intelectual, capacidade de aprendizagem continuada, atuação crítica e ética sintonizada com as necessidades do país, com sólida base humanística e cultural, promovendo e respeitando os direitos humanos e o meio ambiente, conforme preconiza o PPI (UTFPR, 2013b). Entretanto, ao analisar a Matriz Curricular do curso, constatase que apenas uma disciplina sugere o ensino dos princípios defendidos pela EA - a disciplina de Informática e Sociedade. Esta disciplina apresenta características que vão além dos conhecimentos técnicos específicos da área de atuação, tais como impactos da tecnologia (globalização, substituição do trabalho humano); alterações no mercado de trabalho, no modo de produção e nas relações interpessoais; ética e cidadania.

Teoricamente, o projeto de abertura do curso destaca que os alunos poderão cursar disciplinas ofertadas em outros cursos de nivel superior da UTFPR, como enriquecimento curricular e que poderão complementar a formação diversificada almejada. Além dessas disciplinas, os alunos devem necessariamente cumprir uma carga horária em atividades complementares, que são atividades de enriquecimento do processo de ensino-aprendizagem, privilegiando atividades de complementação da formação social, humana e cultural, atividades de cunho comunitário e de interesse coletivo. Essa é uma prática utilizada não só no curso de Tecnologia em Sistemas para Internet, mas sim uma alternativa encontrada dentro da universidade para suprir a carência de discussões e projetos voltados para a questão socioambiental e comunitária na UTFPR. 
Em todos os cursos da universidade, os acadêmicos devem cumprir uma carga horária mínima nessas atividades. É nesse momento que se destaca a necessidade de capacitação do corpo docente para o entendimento da importância dos princípios defendidos pela EA, especificamente nos cursos onde atuam. Sem a devida capacitação, projetos como os de coleta seletiva, por exemplo, equivocadamente podem ser definidores das ações de EA por parte das instituições e de seus cursos superiores, dando a falsa impressão da garantia do trabalho com a EA. Na verdade, essas são ações pontuais e insuficientes perante a complexidade que a temática envolve, justificando-se, assim, a necessidade do entendimento do corpo docente a respeito dos princípios da EA, para a formulação de projetos na área. Percebe-se, neste sentido, que tais princípios no ensino superior devem ainda ser ampliados e debatidos entre o corpo docente na concepção dos projetos pedagógicos dos cursos, para a inserção e amadurecimento da questão socioambiental nas diversas atividades desenvolvidas nos cursos de graduação da UTFPR/Câmpus Toledo.

Há também a necessidade de se buscar a efetivação prática das intencionalidades expostas nesses documentos, sendo que a EA pode ser a mediadora entre a teoria e a prática dentro das instituições de ensino superior. Faz-se necessário a inserção de conhecimentos, valores sociais, éticos e ambientais nos estudos e currículos dos cursos, no sentido de educar para a sustentabilidade socioambiental (GUERRA; FIGUEIREDO, 2014).

Além disso, as universidades devem pautar suas ações de gestão e seus principios fundamentais ancoradas na perspectiva da sustentabilidade socioambiental como política institucional e inseri-las nos documentos institucionais, buscando a coerência entre teoria e prática. Espera-se que essas instituições procurem educar ambientalmente, tornando-se referência e configurando-se como espaços educadores sustentáveis. Para ilustrar um possível caminho para a operacionalização da temática ambiental e dos princípios defendidos pela EA no Câmpus de Toledo, a figura 1 indica o percurso que estes princípios necessitam na formulação do processo curricular existente na universidade analisada. 
Figura 1. Caminhos para a operacionalização dos princípios defendidos pela EA na UTFPR-Câmpus de Toledo

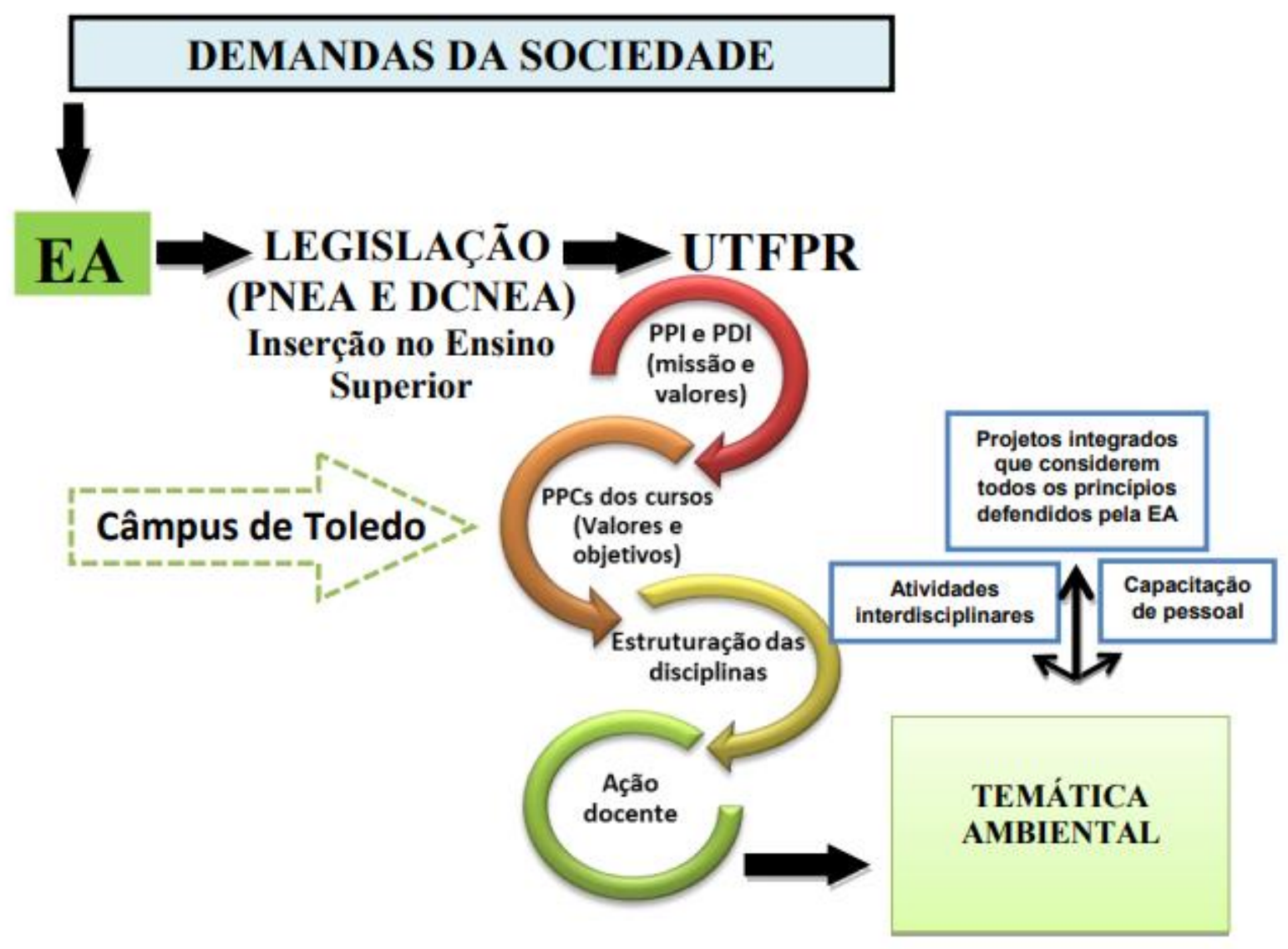

Fonte: Extraído de Quinelato (2015).

Esse é um árduo e longo caminho a ser trilhado pelas universidades e seus cursos, representando uma mudança radical nas instituições como um todo e nas disciplinas dos cursos superiores, pois significa instaurar uma série de mudanças conceituais, metodológicas, estruturais e organizacionais, que permitam um enfoque interdisciplinar (GONZÁLES MUÑOZ, 1996 apud GUERRA; FIGUEIREDO, 2014).

\section{CONSIDERAÇÕES FINAIS}

Conforme apontamentos das principais políticas públicas relacionadas à Educação Ambiental, as ações das universidades devem ser pautadas pelos preceitos defendidos pela EA, numa abordagem que considere a interface entre a 
natureza, a sociocultural, a produção, o consumo, superando a visão despolitizada, acrítica, ingênua e naturalista ainda muito presente na prática pedagógica das instituições de ensino (BRASIL, 2012).

Para atender o que disciplinam as politicas públicas relacionadas à EA, os princípios inerentes à temática devem estar presentes na construção e na operacionalização de todos os documentos institucionais nas instituições de ensino superior, indicando as estratégias para a sua efetiva inserção nas diversas instâncias universitárias. Defende-se também a necessidade da construção coletiva dos documentos institucionais, possibilitando o diálogo entre a comunidade acadêmica que compartilha desses documentos, incluindo-se assim temas diversos, dentre eles discussões institucionais sobre a temática ambiental, no interior dos mesmos.

A não operacionalização dos princípios vinculados à EA aumentam as possibilidades da universidade se tornar uma mera fornecedora de mão de obra para o mundo do trabalho, com profissionais que não refletem sua própria atuação na sociedade, mantendo somente o status quo do sistema capitalista e a manutenção da exploração homem-homem e homem-natureza.

A análise dos documentos institucionais permitiu averiguar que a instituição, mesmo que timidamente, propõe ações e estratégias que constam nas políticas públicas, exemplificado por meio da institucionalização da missão e valores institucionais pautados pela ótica da sustentabilidade, em documentos como o Projeto Político-Pedagógico Institucional (PPI) e Plano de Desenvolvimento Institucional (PDI).

Verificou-se ainda que esses documentos são considerados na construção dos projetos pedagógicos dos cursos, demonstrando a importância da operacionalização dos princípios da EA no PPI e PDI para sua disseminação para outras instâncias da universidade, principalmente pelos seus cursos, procurando desenvolver projetos de pesquisa e a investigação na área da Educação Ambiental, para a produção de tecnologias mitigadoras de impactos negativos ao meio ambiente e à saúde da sociedade como um todo. Porém, essa inserção é insuficiente, tendo em vista que ao longo dos documentos não se apresentam os caminhos a serem seguidos e as estratégias a serem utilizadas para concretizar 
as intencionalidades expostas, tornando-se apenas possibilidades futuras para a universidade e seus cursos e não uma realidade concreta.

Nomeadamente para a UTFPR - Câmpus de Toledo, sem este amadurecimento, torna-se frágil a inserção e a efetivação dos princípios vinculados à EA nos cursos, visto que ela não se materializa para além dos manuscritos. Para avançar, deve-se sair do ideário dos documentos e perpassar pelo ambiente universitário como um todo, pautando a atuação docente nas disciplinas e no desenvolvimento de projetos que estimulem a mobilização social e política e o fortalecimento da consciência crítica sobre a dimensão socioambiental.

Institucionalmente, a UTFPR deve relacionar a tecnologia produzida na universidade com os processos de criação cultural, o meio ambiente e a política, visto que as políticas públicas destacam a necessidade de se fomentar e fortalecer a integração entre ciência e tecnologia, visando à sustentabilidade socioambiental. Além do mais, o tratamento pedagógico do currículo deve ser diversificado, permitindo reconhecer e valorizar a pluralidade e as diferenças individuais, sociais, étnicas e culturais dos estudantes, promovendo valores de cooperação, de relações solidárias e de respeito ao meio ambiente.

\section{REFERÊNCIAS}

BRASIL. Lei $\mathbf{n}^{\circ}$ 9.795, de 27 de abril de 1999. Dispõe sobre a educação ambiental, institui a Política Nacional de Educação Ambiental e dá outras providências, Brasília, 1999a. Disponivel em <http://www.planalto.gov.br/ccivil_03/LEIS/L9795.htm>. Acesso em: 18 maio 2015.

Resolução $\mathbf{n}^{\circ}$ 2, de 15 de Junho de 2012, que estabelece as Diretrizes Curriculares Nacionais para a Educação Ambiental. DOU n ${ }^{\circ} 116$, Seção 1, págs. 70-71 de 18/06/2012.

CHARLOT, Bernard; SILVA, Veleida Anahi da. Relação da natureza com a educação ambiental. In: SATO, Michèle; CARVALHO, Isabel Cristina Moura (Orgs.). Educação Ambiental. Porto Alegre: Artmed, 2005. p. 67-78.

GALVÃO, Maria Cristiane Barbosa. O levantamento bibliográfico e a pesquisa científica. In: Laércio Joel Franco, Afonso Dinis Costa Passos. (Org.). 
Fundamentos de epidemiologia. 2ed. A. 398 ed. São Paulo: Manole, 2010, p. 377. Disponivel

<http://www2.eerp.usp.br/Nepien/DisponibilizarArquivos/Levantamento_biblio grafico_CristianeGalv.pdf>. Acesso em: 13 maio 2015.

GRÜN, Mauro. Ética e educação ambiental: a conexão necessária. 14. ed. Campinas: Papirus. Coleção magistério: formação e trabalho pedagógico. 2012, $126 \mathrm{p}$.

GUERRA, Antônio Fernando Silveira; FIGUEIREDO, Mara Lúcia. Ambientalização curricular na Educação Superior: desafios e perspectivas. Educar em Revista, Curitiba, Brasil, Edição Especial n. 3, p. 109-126, 2014.

LAYRARGUES, Philippe Pomier; LIMA, Gustavo Ferreira da Costa. Mapeando as macrotendências político-pedagógicas da educação ambiental contemporânea no Brasil. In: VI Encontro Pesquisa em Educação Ambiental, 2011, Ribeirão Preto. VI Encontro Pesquisa em Educação Ambiental: a pesquisa em educação ambiental e a pós-graduação. Ribeirão Preto: USP, 2011. v. 0. p. 01-15.

LIMA FILHO, Domingos Leite; QUELUZ, Gilson Leandro. A tecnologia e a Educação tecnológica: elementos para uma sistematização conceitual. In: Educação e Tecnologia, Belo Horizonte: CEFET-MG, v.10, n.1, p.29-35, jan/jul, 2005.

QUINELATO, André Luís. A inserção da temática ambiental no ensino superior: um estudo na Universidade Tecnológica Federal do Paraná/Câmpus de Toledo. 113f. Dissertação (Mestrado) - Programa de Pós-Graduação em Ciências Ambientais, Universidade Estadual do Oeste do Paraná, Toledo-PR, $2015 . \quad$ Disponivel em: <http://www4.unioeste.br/portalpos/media/File/lisangela.birck/AndreLuisQui nelato(1).pdf>. Acesso em: 03 fev. 2016.

REIGOTA, Marcos. O que é Educação Ambiental? 2. ed. São Paulo: Brasiliense, 1998. 62 p. (Primeiros Passos).

SORRENTINO, Marcos; TRAIBER, Rachel; MENDONÇA, Patrícia; FERRARO JUNIOR, Luiz Antonio. Educação Ambiental como política pública. Educação e Pesquisa, São Paulo, v. 31, n. 2, p. 285-299, maio/ago. 2005.

TRINDADE, Diamantino Fernandes. Interdisciplinaridade: um novo olhar sobre as ciências. In: FAZENDA, I. O que é interdisciplinaridade? São Paulo: Cortez, 2008. p. 65-83.

UTFPR. Projeto Politico Pedagógico Institucional (PPI) da UTFPR. Curitiba, 2007a. Disponível em: <http://www.utfpr.edu.br/a-instituicao/documentosinstitucionais/projeto-politico-pedagogico-institucional-1>. Acesso em: 15 maio 2015. 
Projeto Pedagógico do Curso de Tecnologia em Processos Químicos.

Toledo, 2007b. Disponivel em:

$<$ http://www2.td.utfpr.edu.br/processos_quimicos/arquivos/ppc.pdf>. Acesso em: 12 setembro 2015 .

Diretrizes curriculares para os cursos de graduação da UTFPR. Curitiba, 2012a. Disponivel em <http://www.utfpr.edu.br/estruturauniversitaria/pro-

reitorias/prograd/legislacao/copy_of_00812DiretrizesGraduacaoUTFPRVersaoFi nalpagina.pdf>. Acesso em: 28 set 2015.

Projeto Pedagógico do Curso de Engenharia Eletrônica, Toledo, 2012b. Disponivel em: <http://www2.td.utfpr.edu.br/eng_eletronica/ppc.pdf >. Acesso em: 12 maio 2015.

Plano de Desenvolvimento Institucional (PDI) da UTFPR, 2013 - 2017. Curitiba, 2013a. Disponivel em: <http://www.utfpr.edu.br/ainstituicao/documentos-institucionais / pdi-2013-2017/plano-de-

desenvolvimento-institucional-2013-2017/view>. Acesso em 17 maio 2015.

2014a.

Projeto Pedagógico do Curso de Licenciatura em Matemática. Toledo, <http://www2.td.utfpr.edu.br/licenciatura_matematica/arquivos/Documentos / PPC.pdf>. Acesso em: 12 maio 2015.

Toledo . Projeto Pedagógico do Curso de Graduação em Engenharia Civil. <http://www2.td.utfpr.edu.br/eng_civil/pdf/PPCEngenhariaCivil.pdf $>$. Acesso em: 12 maio 2015. 